\title{
SINTOMAS DO BRASIL CONTEMPORÂNEO: TENSÕES DISCURSIVAS E A EDUCAÇÃO PARA A DIFERENÇA
}

\author{
SÍNTOMAS DEL BRASIL CONTEMPORÁNEO: TENSIONES DISCURSIVAS Y \\ EDUCACIÓN PARA LA DIFERENCIA
}

\section{SYMPTOMS OF CONTEMPORARY BRAZIL: DISCURSIVE TENSIONS AND EDUCATION FOR THE DIFFERENCE}

\author{
Juliana Santos Monteiro VIEIRA ${ }^{1}$ \\ Lucas de Oliveira CARVALHO ${ }^{2}$ \\ Dinamara Garcia FELDENS ${ }^{3}$
}

RESUMO: Pretende-se refletir acerca do momento vivenciado no Brasil, entendendo-o como sintoma da Contemporaneidade, pensando práticas e discursos sociais que tensionam-se e rearticulam-se a todo instante. A desconstrução de fatos históricos e a refutação de eventos científicos são alguns dos exemplos que perseguimos nesta reflexão, indagando-nos acerca dos modelos educativos e os modos de ver a História, que estabelecem relações diretas com os aspectos de exclusão social e com as formações subjetivas. Nesse sentido, a verdade parece perder sua posição privilegiada e ocupar, com certa fragilidade, um lugar baseado na crença na figura do sujeito moderno. Nos coube propor novos olhares aos campos do saber, convocandonos a pensar a educação para diversidade como perspectiva indispensável ao enfrentamento da ascensão da barbárie social.

PALAVRAS-CHAVE: Educação. História. Práticas discursivas. Processos de subjetivação. Verdades.

RESUMEN: Tiene la intención de reflexionar sobre el momento experimentado en Brasil, entendiéndolos como síntomas de Contemporaneidad, pensando en prácticas sociales y discursos que se tensan y rearticulan en todo momento. La deconstrucción de hechos históricos y la refutación de eventos científicos son algunos de los ejemplos que buscamos en esta reflexión, preguntándonos acerca de los modelos educativos y las formas de ver la Historia, que establecen relaciones directas con los aspectos de exclusión social y con formaciones subjetivas. En este sentido, la verdad parece perder su posición privilegiada y ocupar con cierta fragilidad un lugar basado en la creencia en la figura del sujeto moderno. Depende de nosotros proponer nuevas perspectivas en los campos del conocimiento, llamándonos a pensar

\footnotetext{
${ }^{1}$ Universidade Federal de Sergipe (UFS), Aracaju -SE - Brasil. Doutoranda no Programa de Pós-Graduação em Educação (PPGED/UFS). Bolsista de Doutorado FAPITEC/SE. Tradução e publicação de artigo financiado pelo Programa de Apoio ao Pesquisador à Pós-graduação (PROAP) - Edital nº 06/2020/PPGED/PROAP/UFS. ORCID: http://orcid.org/0000-0003-3332-6640. E-mail: juhsantosvieira@gmail.com

${ }^{2}$ Universidade Federal de Sergipe (UFS), Aracaju - SE - Brasil. Doutorando no Programa de Pós-Graduação em Educação (PPGED/UFS). ORCID: https://orcid.org/0000-0002-0826-4567. E-mail: lucas.historiando@gmail.com ${ }^{3}$ Universidade Federal de Sergipe (UFS), Aracaju - SE - Brasil. Professora no Programa de Pós-Graduação em Educação (PPGED/UFS). Pós-doutorado (UCM) - Madrid. Doutorado em Educação (UNISINOS). ORCID: https://orcid.org/0000-0001-6471-3876. E-mail: dfeldens@hotmail.com
}

RIAEE - Revista Ibero-Americana de Estudos em Educação, Araraquara, v. 15, n. esp. 3, p. 2314-2331, nov., 2020. E-ISSN: 1982-5587 
en la educación para la diversidad como una perspectiva indispensable para enfrentar el aumento de la barbarie social.

PALABRAS CLAVE: Educación. Historia. Prácticas discursivas. Procesos de subjetivación. Las verdades.

ABSTRACT: It is intended to reflect on the moment experienced in Brazil, understanding them as symptoms of Contemporaneity, thinking about social practices and discourses that strain and re-articulate all the time. The deconstruction of historical facts and the refutation of scientific events are some of the examples that we pursue in this reflection, asking us about the educational models and the ways of seeing History, which establish direct relations with the aspects of social exclusion and with subjective formations. In this sense, the truth seems to lose its privileged position and occupy with a certain fragility a place based on the belief in the figure of the modern subject. We propose new perspectives on the fields of knowledge, calling us to think about education for diversity as an indispensable perspective to face the rise of social barbarism.

KEYWORDS: Education. History. Discursive practices. Subjectivation processes. Truths.

\section{Introdução}

Este artigo buscará refletir acerca de tendências discursivas que se apresentam no Brasil da contemporaneidade, pensando-as enquanto efeitos de práticas constituídas no pensamento ocidental, baseadas em um modelo educativo específico e em um enredo cultural atravessado por perspectivas morais. Nos deparamos atualmente com uma série de proposições e declarações que posicionam fatos históricos do Brasil, registrados e vastamente pesquisados, sob vieses deturpados ou esvaziados de seus sentidos; questões que encontram-se legitimadas e impulsionadas pela lógica da formação de um pensamento médio comum, que tende a ignorar ou ausentar-se das problematizações dos fatos e das teorias científicas. Esse tensionamento da verdade e sua posição de fragilidade não seriam uma questão problemática, não fosse em que se baseiam: na reinvindicação de uma pessoalidade e na crença absoluta nos ideais do sujeito moderno, além de um revigoramento da faceta moral, que deu alicerces ao pensamento metafísico-transcendental a que nos referimos.

É necessário, inicialmente, que compreendamos o que seriam os discursos e as práticas discursivas, conforme entendimento de Michel Foucault (1926-1984), além de acessar seu conceito de dispositivo e sua influência na formação das subjetividades. Entender o que chamamos aqui de Contemporaneidade também parece-nos fundamental, seguindo a perspectiva de Giorgio Agamben (2009), assumindo a atitude ética que evoca a construção de um entendimento do agora neste tempo e fora dele. Os caminhos da Educação e os olhares para

RIAEE - Revista Ibero-Americana de Estudos em Educação, Araraquara, v. 15, n. esp. 3, p. 2314-2331, nov., 2020. E-ISSN: 1982-5587 
a História são aspectos primordiais nesta reflexão, pois suas práticas encontram-se ainda cercadas dos formalismos e naturalizações, pouco problematizadas em suas relações com o passado, ratificando um processo semiformativo sustentado pelos convencionalismos culturais, conforme cita Theodor Adorno (1903-1969).

Utilizaremos Marc Bloch (1886-1944) em sua reflexão sobre a necessidade do dinamismo na História, negando-a como objeto neutro e linear, evocando uma história do acontecimento; acessaremos então, alguns discursos em voga no Brasil contemporâneo, recorrendo a Friedrich Nietzsche (1844-1900) e sua crítica aos valores morais, assim como sua crítica à ciência como criadora de narrativas fixas, que não deslocam perspectivas ascéticas anteriores, que falham na transmissão de seu real funcionamento, e que terminam por permitir o revigoramento de ideais retrógrados e maléficos para a humanidade.

Nesse sentido, parece-nos fundamental olhar acuradamente os modelos educativos e os aspectos culturais que justifiquem as consequências dos caminhos percorridos pelo Brasil, que desenrolam-se na contemporaneidade em uma série de discursos de ordem moral, além da opção feita pelos âmbitos dito "científicos" por um viés totalizante e criador de novas hegemonias, que visam a regência da vida particular e alheia através dos saberes, assim como a veiculação de discursos de controle e dominação. Pensando em possíveis meios de transformar o cenário de barbárie contemporânea, a educação para a diferença e para a diversidade buscaria amparar-se nos movimentos singulares e na diferenciação junto ao coletivo, constituindo novas possibilidades de produzir-se subjetivamente e transpor representações universalizantes.

\section{Práticas discursivas e o esgarçar das verdades: a Educação, a História e as subjetividades contemporâneas}

Enquanto proposta inicial, demonstra-se necessário problematizar o que entenderemos neste texto por discurso, seguindo a perspectiva de Michel Foucault (1979), assim como o conceito de contemporaneidade, explanado por Giorgio Agamben (2009). Ambos referem-se à base desta discussão, sob intenção de localizar-nos no seio deste determinado momento vivido, compreendendo-o como sintoma da produção e da constante reformulação das tecnologias de poder.

O discurso, para Foucault (1996), se realiza como um conjunto de enunciados definidos por condições de existência, que são formadores e produtores de subjetividades. Com isso, Foucault desvela pressuposições universais e essencialistas do imaginário social acerca do 
discurso e articula a elas modalidades institucionais e sociais de aparição, circulação e seleção. As práticas discursivas são conjuntos de regras historicamente situadas, muitas delas anonimamente naturalizadas e modificadas incessantemente. A palavra é, portanto, uma materialidade, que cria novas materialidades; sintoma de um longo processo de crenças; representação que emerge junto a novos regimes de poder e noções de sujeito. O discurso então, faz funcionar, reproduzir, reforçar novas relações de poder/saber, é produtor de individualidades.

Desse modo, não há nada "por trás" do discurso, pois os enunciados e suas relações são próprios de seu funcionamento, compreendendo a linguagem como constituidora de práticas concretas, formadora do objeto de que falam. Uma das premissas desta interpretação do discurso é não acreditar na existência de estruturas permanentes, pois apesar da formação discursiva caracterizar-se pela regularidade prática, ela está sempre em relação com os campos de saber, com as matrizes de sentido, com os regimes de verdade: a palavra só tornar-se discurso quando está dotada destas forças. De forma primordial, as leis e propriedades dos discursos são efeitos do campo discursivo, assim como os sujeitos sociais e as subjetividades. Não cabe então, uma análise do conteúdo destes discursos, mas sim, entender por que os mesmos relacionamse com os acontecimentos (FISHER, 2001).

Os dispositivos são instrumentos que se estabelecem nas condições de possibilidade dos acontecimentos, sendo capazes de orientar, controlar, regular as práticas e condutas dos sujeitos, que estão imersos em processos de subjetivação, obstruindo as possibilidades de constituição de modos de existência singulares. Esses dispositivos de governabilidade têm origem no processo de hominização, de separação do vivente de si e de seu ambiente, exercendo função estratégica de manipulação das relações de força, orientando-as ou bloqueando-as, se configurando como redes linguísticas ou não (FOUCAULT, 1996).

Conforme salienta Arenas e Trujillo (2020), na análise de documentos e relatórios internacionais, desde meados de 1940 os discursos educacionais sustentam as concepções da Teoria do Capital Humano ${ }^{4}$, onde o conhecimento é visto como via de progresso e desenvolvimento econômico, tornando a educação para a competitividade um método de política social de Estado, voltado ao emprego e a cidadania enquanto fatores de inovação e

${ }^{4}$ A Teoria do Capital Humano surge em meados dos anos 50 nos EUA, formulada por Theodore Schultz, em algumas de suas obras ( $O$ valor econômico da educação - 1963; O Capital Humano: investimentos em educação e pesquisa - 1971), sendo vencedor do Prêmio Nobel de Economia em 1968. Essa concepção formula o entendimento de que a educação e a qualificação profissional são pressupostos primordiais para a produtividade econômica. Além de fortalecer a concepção tecnicista da educação, essa teoria serve de base para o deslocamento do âmbito individual em relação aos problemas sociais, posicionando o "si mesmo" em ligação direta com o capital.

RIAEE - Revista Ibero-Americana de Estudos em Educação, Araraquara, v. 15, n. esp. 3, p. 2314-2331, nov., 2020. E-ISSN: 1982-5587 
produtividade. O discurso científico pertence a este viés homogeneizador da cultura, voltado à institucionalização e à racionalização da vida social, inferindo sobre temas essenciais como o meio ambiente, os direitos humanos, a democracia, etc. Essas lógicas globalizantes e recomendações unilaterais terminam por refletir nos campos de ação social e política cotidianos.

\begin{abstract}
A contemporaneidade, portanto, é uma singular relação com o próprio tempo, que adere a este e, ao mesmo tempo, dele toma distâncias; mais precisamente, essa é a relação com o tempo que a este adere através de uma dissociação e um anacronismo. Aqueles que coincidem muito plenamente com a época, que em todos os aspectos a esta aderem perfeitamente, não são contemporâneos porque, exatamente por isso, não conseguem vê-la, não podem manter fixo o olhar sobre ela (AGAMBEN, 2009, p. 59, grifo nosso).
\end{abstract}

Contrapondo as ideias tradicionais que posicionam a Contemporaneidade como mera periodização histórica, Agamben (2009) preocupa-se com sua conceitualização e possibilidade de delimitação. O contemporâneo é retorno que não cansa de se repetir, é uma temporalidade do presente; é lâmpada que ofusca, mas permite ver; só ele existe, pois cada vez é "o agora" que se apresenta, é objeto e elemento do agora. Para o autor, aqueles que se dedicam a pensar o contemporâneo precisam partir de uma atitude ética de recusa e estranhamento de sua época, de reconhecimento dos pontos de cisão e de ruptura, de modo a colocar seu olhar sob o arcaico e sob o atual. Essa postura ética é então, uma postura perante o tempo, que tem como objetivo compreender a atualidade buscando transpor seus dispositivos de sujeição. Inúmeros esgotamentos estão sendo produzidos, tendo em vista o duplo efeito que se reflete na cultura: de um lado, o conturbado movimento político do Estado Moderno, a reivindicação de grupos minoritários e o surgimento de uma nova estética do fascismo; de outro, o cotidiano prático e supostamente pacífico, no qual os sujeitos cumprem suas determinações sociais. Esses esgotamentos se produzem na inércia das capacidades políticas, no campo do trabalho, na manutenção de políticas de Estado excludentes, na norma moral estabelecida, entre outros aspectos. Demonstra-se fundamental então compreendermos o tempo como esse acontecimento do agora, como somos fruto destes acontecimentos e como as "fraturas" nos podem servir enquanto compromissos para o olhar ao escuro do nosso tempo. 


\section{Por que estamos surpresos?}

Debate-se hoje nacionalmente e também em um âmbito mundial sobre o recrudescimento de certas forças autoritárias (como é o caso do fascismo), bem como o fortalecimento da discussão sobre temas que ao menos em nosso imaginário pareciam estar pacificados. Nesse sentido, é muito comum vermos discursos reivindicando a ciência, a educação, o conhecimento, a história como ferramentas capazes de remediar o delírio de alguns e de combater as práticas obscurantistas que vêm se tornando tão comuns em nossa atualidade. Compreendemos a reivindicação, mas é preciso atentar para as armadilhas que podem se produzir nesse campo de luta, afinal o campo dos saberes, suas instituições e sua produção não podem ser postos de forma alheia, como se não possuíssem responsabilidades, como se não fossem permeados por relações e disputas de poder. Assim, mais especificamente no que se refere à História e à Educação, demonstra-se necessário fazermos uma reflexão sobre como estas práticas de alguma forma também colaboram para o revigoramento desses ideais retrógrados.

Na educação, Theodor Adorno (2006) será um grande representante dos pensadores que estarão preocupados em entender no pós-guerra os caminhos que levaram à barbárie e como evitar que estes acontecimentos voltem a se repetir no presente. Para Adorno (2006), a educação é portadora de um papel indispensável e fundamental no mundo: evitar a volta ao estado de barbárie através da contestação e da resistência. Para isso, necessita pensar não somente no indivíduo ou na formação, mas também na relação deste com o meio social em que está inserido, sempre através do pensamento crítico. Nesse sentido, uma educação sem o desenvolvimento de um pensamento crítico capaz de expor as contradições de toda e qualquer relação da vida social, o enfraquecimento e a redução da racionalidade a uma condição meramente coisificada e instrumental são algumas pistas que Adorno (2006) levanta como fatores que contribuíram para o estado de barbarização para o qual o mundo foi tragado na primeira metade do século XX e que nos servem de sintomas, guardadas as devidas proporções, diante do que se passa no presente.

Para pensarmos como desenvolver esse pensamento crítico, Adorno (2006), em um texto intitulado "Como Elaborar o Passado", propõe pensarmos na necessidade de enfrentarmos as causas e as contradições que fizeram parte da constituição de qualquer sociedade, em vez da produção de amenidades, ou de distorções que tentam reduzir a violência e a barbárie a um ponto fora da curva, a um mero excesso. A falta do enfrentamento franco e 
crítico dessas questões é o que mantém viva e pulsante em nosso presente ideias e concepções autoritárias como, por exemplo, o fascismo ou nazismo.

O nazismo sobrevive, e continuamos sem saber se o faz apenas como fantasma daquilo que foi tão monstruoso a ponto de não sucumbir à própria morte, ou se a disposição pelo indizível continua presente nos homens bem como nas condições que os cercam (ADORNO, 2006, p. 29).

Suas palavras soam proféticas em nossos dias atuais, tendo em vista que por várias partes do mundo ideais tirânicos voltam a ganhar força. Temos, por exemplo, acompanhado o crescimento de grupos e partidos ultranacionalistas sustentados em ideias neonazistas e neofascistas na Europa. No Brasil, por sua vez, vemos também uma crescente onda ultraconservadora somada a um fundamentalismo religioso que depõe contra a sociedade livre que almejamos, mostrando-nos que não nos resolvemos com nosso passado colonial, aristocrata e escravocrata. Todos esses fantasmas que nos rondam no presente só evidenciam o que o autor já alertava em suas reflexões.

Mas, mesmo acontecendo isto, o perigo permanece. O passado só estará plenamente elaborado no instante em que estiverem eliminadas as causas do que passou. $\mathrm{O}$ encantamento do passado pôde manter-se até hoje unicamente porque continuam existindo as suas causas (ADORNO, 2006, p. 49).

Nesse debate em torno dos continuísmos e recrudescimento de forças dentro dessa relação entre presente e passado, a História tem sido muito reivindicada como o campo do saber capaz de nos ajudar a compreender a dimensão do paradigma que estamos enfrentando. Mas é preciso saber de qual História, de qual fazer historiográfico estamos falando, pois dentro de suas práticas há também as intencionalidades, as lutas de poder, as condescendências e os conformismos diante de seu exercício. A História não é neutra, apesar de alguns ainda buscarem sustentar esse mito; assim, uma História que possa ajudar a nos debruçarmos sobre essas questões contemporâneas necessita ser um fazer crítico.

Marc Bloch (2002), historiador francês, quando escreve “Apologia da história ou o oficio do historiador", se propõe a responder uma pergunta em tese simples: "para que serve a História?”. Nessa empreitada, promoveu uma série de subversões que iam de encontro com os valores positivistas das concepções tradicionais do fazer historiográfico. Bloch (2002) rompe com a ideia da História como um campo do saber dedicado ao passado ou mesmo com a ideia de que é o objeto que move as problematizações. Para o historiador, a relação com o passado sempre se dá a partir da dinâmica do presente, de questões, de problemas que surgem no 
presente, logo é a história um campo dinâmico do saber e não imóvel dentro de uma linearidade - passado/presente/futuro.

Sendo a história dinâmica, são dinâmicas também as problematizações e os olhares sobre o objeto, logo não pode ser a História uma prática de verdades imóveis e irrefutáveis, não pode ser também o objeto, aquilo que faz os problemas se moverem, e sim o contrário, são as problematizações em cada atualidade que movem os objetos em busca de suas causas, e como diz Bloch (2002): “Resumindo tudo, as causas, em história como em outros domínios, não são postuladas, são buscadas" (p. 159). Discutindo um pouco mais profundamente acerca de nosso modo metafísico de pensar, entendemos a constituição do pensamento ocidental e da ciência histórica cercados pela busca da verdade, por visões essencialistas, datas específicas, pela procura da origem. Negligencia-se para isso, as diferenças e as inconsistências dos acontecimentos em detrimento de um todo, buscando uma lógica, algo que se estabeleça enquanto fato histórico.

O tempo é tão complexo que faz e desfaz, não só dá a vida e a dissipa, como a marca de forma irrevogável. Portanto, ao analisarmos o tempo de uma determinada época, percebemos a densidade do pensamento, compreende-se as irradiações otimistas e derrotistas, as euforias e as neuroses, os temas brandos e os candentes. No campo da educação, encontramos tempos de trevas e iluminados, ignorâncias e tempos esclarecidos, mais canónicos e mais tendentes para a rebeldia, mais obedientes e independentes. O tempo e o espaço condensam definitivamente a concepção da sociedade. Se viajarmos pela história, quantas épocas se encontram provenientes de diferentes concepções sociais, de modelos educacionais diferentes, de diversas estruturas de desenvolvimento, de formas distintas de organização da vida! (VAZQUEZ; DUQUE, 2020, p. 29).

Conforme salientam Vazquez e Duque (2000), o tempo presente é feito de descontinuidades, a partir do cruzamento de processos. Não só a História vem desconstruindo os ideais modernos que tem na consideração da ciência e do racional uma instância absoluta do pensamento, buscando compreender o acontecimento como apenas um sintoma a partir de uma luta constante e múltipla; teorias fortemente legitimadas no imaginário coletivo, como as ciências médicas e físicas, também vem sendo desconstruídas e postas em dúvida. Não se julga aqui a negatividade ou positividade deste fato, apenas compreendem-se os questionamentos como parte dos sinais que habitam os tempos contemporâneos. Nas escolas e nas salas de aula, porém, as práticas relacionadas ao ensino de História ainda estão permeadas por uma forte tradição da linearidade histórica, dos formalismos e das narrativas dos grandes acontecimentos. As políticas educacionais brasileiras parecem sempre estar voltadas a perspectivas localizadas, 
priorizando a resolução imediata, baseadas em metas do sistema educacional, sob uma espécie de “miopia do urgente" (VAZQUEZ; DUQUE, 2020).

$\mathrm{Na}$ medida em que a História se porta como um sequenciamento de fatos ou um depositório de narrativas antropocêntricas, perde-se a capacidade do exercício crítico de problematização sobre questões que nos são locais e atuais. Além disso, uma perspectiva demasiadamente veloz e rasteira da História, de buscar no tempo suas eventuais causas em prol de uma construção meramente informativa, atende a interesses puramente técnicos e produtivistas. A História como uma prática informativa produz uma quebra entre o passado e a atualidade e cria um fosso onde se impede de compreender os desdobramentos, os refinamentos, os sobressaltos que situam-se na mesma.

Adorno (2006) faz uma reflexão importante sobre o processo formativo e como este sofreu uma distorção ou mesmo uma deformação na medida em que se tornou submisso a determinados aspectos da formação social, onde a cultura por sua vez se tornou também submissa a critérios objetivos da produção econômica estabelecida. Em outras palavras, o processo de formação se tornou enfraquecido ou condicionado a uma pauta objetiva, econômica, sustentada e referendada por um convencionalismo cultural determinado dentro das estruturas de formação social. A redução da formação a um estado de semiformação criou prisões para o pensamento crítico, na medida em que engendra processos conciliatórios, obscurece e oculta as contradições inerentes ao processo formativo de qualquer sociedade, naturalizando e essencializando o que é construção social. Desta maneira, em uma sociedade onde as contradições são amenizadas e ocultadas, não há possibilidade para outra coisa a não ser a conformação e a adaptação. Pois, a cultura, o pensamento e os processos formativos se tornam meros replicadores (ADORNO, 2006). A educação e o próprio campo histórico, nesse contexto, em vez de assumirem um papel crítico se reduzem, sem oferecer resistência alguma, à lógica reprodutivista e adaptativa dos sujeitos ao estatuto estabelecido. Parece claro que uma reflexão sobre o recrudescimento de forças autoritárias, o recrudescimento também no campo das ideias na atualidade, não pode ser feita compreendendo essas forças como algo exterior, que toma de assalto as mentes e corações das pessoas. Fazer uma reflexão sobre essas questões exige compreendê-las como frutos da própria produção social. Nesse sentido, o saber, a ciência, a educação e a história não podem ser tratadas como construções purificadas, isentas de responsabilidades e de intencionalidades. É preciso fazer esse reconhecimento porque, só assim, será possível exercer resistências contra o preconceito, a violência, a tirania, a coisificação do pensamento, a difusão e a naturalização da barbárie na sociedade. 


\section{Discursos circulantes e a luta das narrativas: moralidade, cisões com a ciência e o tremor das verdades}

Alguns discursos circulantes no momento brasileiro atual ilustram as problemáticas que buscamos discutir neste texto. Neles percebemos claros questionamentos da ciência e de fatos históricos supostamente já estabelecidos desde séculos anteriores, assim como perspectivas de verdade estremecidas, que tensionam os lugares de administração e autoria daquilo que é dito. Sob outra camada, emergem aspectos morais muito visíveis, que nos ligam a um passado recente ou não tão recente, e que evidenciam em que lugares a humanidade costuma agarrar-se quando se ameaçam rígidos construtos identitários.

Como um primeiro exemplo desse tipo de movimento, ilustramos os crescentes pedidos pelo reestabelecimento do Império monárquico no Brasil. Herdeiros dos dois imperadores do Brasil (Pedro I e Pedro II), os Orleans e Bragança, justificam os desvios éticos ocorridos com os políticos brasileiros e os escândalos de corrupção como fundamentos para o movimento. Em redes sociais, o grupo conta com mais de 13 mil seguidores, além de estarem formatando grupos em vários estados do país.

Apenas a título de lembrança, a Monarquia no Brasil se deu entre 1822 e 1889, passando por diversas fases históricas, dando continuidade direta à linhagem real portuguesa de D. João VI. A característica política primária deste período é a centralização do poder, tendo como súditos do imperador os imigrantes europeus, os índios nativos, os africanos e afrodescendentes, ou seja, classes populares e trabalhadores. Diversas foram as revoltas regionais deste período, à exemplo da Cabanagem (1835-1840) no Pará, da Sabinada (1837-1838) na Bahia, da Balaiada (1838-1840) no Maranhão, da Guerra dos Farrapos (1835-1845) no Rio Grande do Sul, todos demonstrando a resistência da população ao sistema monárquico e resultando em milhares de mortes de civis. Este período ficou marcado também pela estruturação das Forças Armadas Brasileiras, marcadamente utilizada para defender os interesses do Estado (VIANA, 1996). A ausência de distinção público/privado e os traços de clientelismo estruturaram o modelo de colonização no Brasil, o que nos faz expandir o entendimento acerca dos momentos atuais, entendendo-os não como fatos isolados e novos, que se iniciaram a poucos anos por um partido ou agente político localizado. Além disso, a herança de país escravocrata já pressupõe uma dívida social grandiosa. O período monárquico legitimou os privilégios e a manutenção da elite econômica do país no poder, assim como tornou o controle social mais abrangente, pois envolvia-se em questões religiosas e morais (VIANA, 1996).

Outro discurso que tem ganhado espaço, inclusive dentro das escolas brasileiras, é o da refutação do período histórico que compreende a Ditadura Militar (1964-1985) e a solicitação

RIAEE - Revista Ibero-Americana de Estudos em Educação, Araraquara, v. 15, n. esp. 3, p. 2314-2331, nov., 2020. E-ISSN: 1982-5587 
de uma parcela da população por uma nova intervenção militar no país. Durante 20 anos o Brasil viveu a eliminação de opositores, jornalistas, artistas, ou qualquer um chamado "subversivo", como política de Estado; o ambiente criado pela Ditadura era de repressão, vigilância, tortura sistemática, prisões ilegais e desaparecimentos. Com o falso aval de "leis" serviu-se do Estado para corromper instituições e alimentar interesses próprios dos militares no poder (REIS, 1988). Vários aspectos contrários aos trabalhadores podem ser destacados no período da Ditadura: falta de saneamento básico, a saúde precária e apenas para trabalhadores formais, a falta de fiscalização das obras ou conselhos fiscais do dinheiro público aplicado, e acima de tudo, a possibilidade de suspensão dos direitos políticos de qualquer cidadão, por qualquer motivo encontrado pelo regime. O livre-pensar não era uma opção e havia um rigoroso controle das informações e das liberdades individuais, tendo como prioridade da educação a transmissão da ideologia dominante. Para os que evocam o desenvolvimento do país neste período como justificativa da crença em um novo período militar, relembramos o aumento da dívida externa que revelou-se impagável na primeira década da redemocratização (REIS, 2000).

O que torna essa situação relevante nos tempos atuais é a realização de atos antidemocráticos, como já vemos em precedentes abertos na história recente. Os conhecimentos históricos produzidos no período de 20 anos de Ditadura parecem não ter sido colocados de forma crítica no ensino de História no Brasil, visualizando a consciência política dos brasileiros, o reconhecimento dos militares e das Forças Armadas e de muitas instituições que apoiaram o regime ditatorial, como algozes e financiadores da morte de milhares de civis. Saudações a torturadores e estupradores em Congresso Nacional, eleições pautadas em notícias falsas e manipulação da informação e da mídia, resgate de valores morais e de dominação do corpo e do pensamento, enfraquecimento dos direitos dos trabalhadores, censura à arte e ao jornalismo e utilização das leis para benefício próprio e de terceiros, são alguns exemplos do tom da política brasileira contemporânea.

Outro discurso que aflorou sob forma de prática política discorre acerca da chamada "Ideologia de Gênero": enunciados de viés religioso que tem por objetivo resgatar o já enfrentado pensamento biologizante acerca do gênero. Com a emergência de novos paradigmas acerca da construção do eu e a proposição de papéis sexuais mais flexíveis, além da reflexão acerca da violência contra a comunidade LGBTQIA+ crescente no país, teve como resposta a perigosa junção entre o pensamento religioso conservador e as políticas educacionais. A

${ }^{5}$ EGGERT, E.; REIS, T. Ideologia de Gênero: uma falácia construída sobre os planos de educação brasileiros. Educ. Soc., Campinas, v. 38, n. 138, p.9-26, jan./mar. 2017. Disponível em: https://www.scielo.br/pdf/es/v38n138/1678-4626-es-38-138-00009.pdf. Acesso em: 5 jul. 2020. 
interferência e o alvo na desconstrução de direitos humanos materializaram-se no discurso da ideologia de gênero, numa tentativa de desqualificação do movimento, de suas necessidades de reconhecimento e de defesa. O que se compreende neste discurso é uma tentativa de manutenção dos dois horizontes tradicionais: a heteronormatividade e o patriarcado. A tentativa de manutenção já seria esperada, tendo em vista o peso ocupado por essas formas hegemônicas de existência. A expansão da perspectiva de gênero, porém, não simboliza a possibilidade de destruição das famílias, mas a possibilidade de desconstrução delas, ampliação de seus modelos, inclusão de suas matrizes, que não são patriarcais e tradicionais na realidade prática. A crença na ideologia de gênero é mais um arcabouço de enunciados, de distorção de fatos históricos e tentativas de esvaziamento e universalização do pensamento médio comum, dentre muitos disseminados no Brasil contemporâneo.

O viés moral que o pensamento Ocidental adquire após o advento da doutrina judaicocristã parece aflorar na contemporaneidade, relembrando-nos sua associação com a dinâmica metafísica-transcendental e sua prevalência no empreendimento universalizante de uma racionalidade, sempre dependente de ídolos e muletas externas dissociadas do plano das materialidades. Do cristianismo às ideias modernas a mesma ética se desenrola, sob uma moral de desligamento dos instintos, separação homem-natureza, sobrepujando-a e inferiorizando-a, intencionando o controle e o treino dos corpos para melhorar sua utilidade e produtividade, tendo ainda as mesmas fontes de valores. Esse modelo de homem fraco, amante da razão, está imerso no conformismo e na apatia e tem no caos da vida seu maior receio e na manutenção da coletividade universalizada seu maior objetivo (NIETZSCHE, 2009). Reconhecemos então, os sucessivos platôs que se engendram na paralisia do pensamento, ligados às armadilhas do conhecimento e na ilusão do controle sob os objetos, que referendam uma associação entre a verdade e o mito, mesmo que a ciência o tente renegar.

A ciência, desde sua primeira iniciativa, foi rechaçada por motivos político-ideológicos e religiosos, pois contestou diretamente grupos hegemônicos no poder. Ao mesmo tempo, em seu processo legitimador, cria novas hegemonias, novos discursos e enunciados em formato de verdades estabelecidas. Esses polos de força em constante luta resultam nos dilemas que vivemos na Contemporaneidade. Os equívocos e distorções demonstram-se provenientes da falha na transmissão do pensamento científico nos ambientes educativos, que não exploram seus processos de investigação da realidade, suas errâncias, suas aplicações na vida cotidiana. A política do pós-fato ou da pós-verdade como muitos pesquisadores têm estudado ${ }^{6}$ configura-

${ }^{6}$ Alguns exemplos: DUNKER e TIBURI "Ética e pós-verdade" (2017); PAULA; BLANCO; da SILVA "PósVerdade e fontes de informação: um estudo sobre fake news" (2018); GENESINI "A pós-verdade é uma noticia

RIAEE - Revista Ibero-Americana de Estudos em Educação, Araraquara, v. 15, n. esp. 3, p. 2314-2331, nov., 2020. E-ISSN: 1982-5587 
se como um novo modelo de autoritarismo nacionalista, que nega as evidências científicas, na maioria das vezes, em nome de uma ideologia econômica ou de mercado, ligados às transformações do sistema capitalista.

\begin{abstract}
Em si mesmas, as regras são vazias, violentas, não finalizadas; são feitas para servir a isto ou aquilo; elas podem ser burladas ao sabor das vontades de uns ou de outros. O grande jogo da história será de quem se apossar das regras, de quem tomar o lugar daqueles que a utilizam, de quem se disfarçar para perverte-las, utilizá-las pelo avesso e voltá-las contra aqueles que as tinham imposto; de quem, introduzindo-se no complexo aparelho, o fará funcionar de tal forma que os dominadores se encontrarão dominados por suas próprias regras (FOUCAULT, 2005, p. 283-284).
\end{abstract}

A ciência, portanto, não é partidária, mas é eminentemente política. O equilíbrio entre as instâncias do absolutismo e da negação necessita ser estimulado por meio da reflexão crítica e compreensiva dos fatos, tendo como agentes diretos os educadores, os jornalistas, os intelectuais comprometidos com a investigação, não da ordem das essências, mas das pluralidades. Novas discussões éticas e morais são necessárias, desvelando os interesses e as vicissitudes, na articulação do corpo/homem com a história. $\mathrm{O}$ esvaziamento do pensamento médio brasileiro serve a interesses específicos que devem ser expostos, para que se gerem rearticulações e resistências.

Alguns exemplos diretos destes questionamentos quanto à ciência, que trazem consequências concretamente no cotidiano, são, por exemplo, movimentos como o "Antivacina"7, que configuram-se como pessoas partidárias da não imunização de crianças. Essa vertente cresce em todo mundo e forma significativos grupos no Brasil, fazendo a cobertura vacinal despencar drasticamente nos últimos anos no país. O movimento, antes influenciado por religiosos ou opositores à indústria farmacêutica, hoje ganha adeptos cada vez mais jovens e ligados às questões "naturais", negando a medicina alopática. O movimento cresceu a partir de relatórios e estudos questionáveis e de notícias falsas que circulam nas redes sociais, em consonância com a profunda desconfiança da população perante seus governantes.

Um relatório da Organização Mundial de Saúde incluiu o Movimento Antivacina como um dos dez maiores riscos à saúde da população em todo mundo, em uma lista que inclui os

falsa" (2018); LLORENTE e CUENCA Dossiê “A era da Pós Verdade: realidade versus percepção"(2017, n” 27).

${ }^{7}$ NASSARALLA, A. "Dimensões e consequências do movimento antivacina na realidade brasileira" (2019). Disponível em: http://revistas.unievangelica.com.br/index.php/educacaoemsaude/article/view/3813/2651. Acesso em: 5 jul. 2020 .

RIAEE - Revista Ibero-Americana de Estudos em Educação, Araraquara, v. 15, n. esp. 3, p. 2314-2331, nov., 2020. E-ISSN: 1982-5587 
vírus Ebola, HIV, Zika e dengue ${ }^{8}$. O movimento ameaça reverter quadros de progresso no combate a doenças erradicadas e evitáveis, que salvam de 2 a 3 milhões de pessoas por ano. Outro questionamento teórico quase inimaginável, mas que ganha cada dia mais adeptos e seguidores em vários lugares do mundo, é o Movimento Terraplanista ${ }^{9}$. Este visa questionar todas as Leis de Kepler, que datam do século XV e fundamentam a Física dos Astros, além do próprio Heliocentrismo de Copérnico e as leis da gravidade de Newton. Fundada nos EUA, a "Flat Earth Society" (Sociedade da Terra Plana) surge na metade do século XX, mas ganha força no ano de 2009, com novos membros e novas teorias contestadoras. Baseiam-se, basicamente, em textos conspiratórios, que incluem o envolvimento da maçonaria e dos Illuminatis, questionando conceitos legitimados na ciência por mais de 2 mil anos. Recentemente, a Conferência Internacional da Terra Plana (FEIC, sigla inglês) anunciou um cruzeiro com destino aos "limites da terra", que acreditam ser um imenso muro de gelo, a Antártida, que nos separaria do "exterior".

Esses dois exemplos ilustram a onda dos discursos anticientíficos emergentes na contemporaneidade, que são potencializados pela democratização da mídia, que ao mesmo tempo em que amplia o acesso à informação, alimenta raciocínios motivados pelos "achismos" e pelas percepções pessoais das situações. Ilustrada como perspectiva, a verdade adquire uma frágil posição, pois, sustentados pela construção de um “eu” moderno, supostamente autônomo e liberto, reivindica-se o caráter pessoal das crenças.

A adesão do ideário tecnológico como discurso de desenvolvimento para o Brasil possui grande responsabilidade diante do cenário exposto, tendo em vista a exclusão das problematizações sociais e o esvaziamento da perspectiva do trabalho humano, aderindo apenas aos enunciados mundiais de competitividade das "sociedades da informação" e a conceitos mercadológicos como os de "produtividade e empreendedorismo", priorizando o domínio de habilidades à reflexão crítica voltada à uma educação social (BAPTISTA; PALHANO; DINIZ; SILVA, 2020).

Essas tendências evocam a necessidade de buscarmos explicação dos fenômenos dentro da cultura, analisando suas formas de desenvolvimento e identificando as práticas discursivas

${ }^{8}$ SBMT, Sociedade Brasileira de Medicina Tropical: Movimento antivacina é uma das dez ameaças para a saúde mundial. 11 abr. 2019. Disponível em: https://www.sbmt.org.br/portal/anti-vaccine-movement-is-one-of-the-tenthreats-to-global-health/. Acesso em: 05 jul. 2020.

9 SERRA, "Educação Geográfica, dilemas e desafios contemporâneos" (2019). Disponível em: http://periodicos.puc-rio.br/index.php/revistaeducacaogeograficaemfoco/article/view/1153/653. Acesso em: 5 jul. 2020 .

PAOLILLO. "The Flat Earth phenomenon on Youtube" (2018) - Indiana University. Disponível em: https://firstmonday.org/ojs/index.php/fm/article/view/8251. Acesso em: 5 jul. 2020.

RIAEE - Revista Ibero-Americana de Estudos em Educação, Araraquara, v. 15, n. esp. 3, p. 2314-2331, nov., 2020. E-ISSN: 1982-5587 
que constituiriam o jogo do verdadeiro e do falso. As formas de subjetivação estão constantemente atravessadas pelos dispositivos de poder, renovam-se e reinventam-se variando em intensidade não-linear, não necessariamente constituindo escalas de evolução ou progresso. Esses movimentos de retroação dos discursos, portanto, fazem parte do percurso humano, que parece ter na crise uma espécie de gerência da vida, pois encontram-se impossibilitados e engessados diante da criação de outros possíveis.

Sob a perspectiva deleuziana da diferença ${ }^{10}$, é possível pensar para além da busca da integração, guiadas pelas metas do sistema escolar, compreendendo a educação para a diferença como este aprendizado voltado à temporalidade do acontecimento, sendo este o movimento no qual a singularidade é produzida diante das virtualidades que orbitam o Ser e, que, quando se encontram, produzem novas singularidades. O processo de diferenciação se renova dinamicamente, não podendo ser reduzido à atributos internos ou externos, pois transpõe qualquer forma de representação ou universalização em categorias, considerando cada indivíduo algo singular, expressão unívoca de cada Ser (LANUTI; BAPTISTA; RAMOS, 2020). Nesse sentido, um novo processo formativo necessita ser construído/inventado, amparado nas perspectivas da diferença e da diversidade, tendo em vista ultrapassar e dirimir as exclusões e desconsiderações dos direitos fundamentais tão presentes no cenário de barbárie social, frutos da intolerância, da violência, da negação do outro.

\section{Considerações finais}

Buscamos discutir neste texto questões consideradas relevantes por sua atualidade e urgente necessidade de problematização, tendo em vista a constituição de uma cultura que tem possibilitado o revigoramento de ideais tradicionalistas e obsoletos. De início, foi importante apontar os entendimentos de Michel Foucault a respeito da constituição dos discursos, das práticas discursivas e dos dispositivos que incessantemente produzem subjetividades. Importante demarcarmos também como olhamos para nossas problematizações em termos de sua localização no tempo e espaço social. Para isso, buscamos em Agamben (2009) a possibilidade de delimitar o Contemporâneo como o momento de fratura, de exposição, de perceber o escuro no ontem que dizemos que é o hoje; sendo intempestivo, o contemporâneo é

10 “Quando o corpo conjuga seus pontos notáveis com os da onda, ele estabelece o princípio de uma repetição, que não é a do mesmo, mas que compreende o Outro, que compreende a diferença e que, de uma onda e de um gesto a outro, transporta essa diferença pelo espaço repetitivo assim constituído. Aprender é construir esse espaço do encontro com signos, espaço em que os pontos relevantes se retornam uns aos outros e em que a repetição se forma ao mesmo tempo em que se disfarça” (DELEUZE, 2006, p. 48-49).

RIAEE - Revista Ibero-Americana de Estudos em Educação, Araraquara, v. 15, n. esp. 3, p. 2314-2331, nov., 2020. E-ISSN: 1982-5587 
questionador do tempo presente, apesar de acreditar apenas no agora; rizomático, entende a existência de um limiar inapreensível.

Em um segundo momento, demonstrou-se fundamental compreender a educação como portadora de um papel indispensável na consolidação do olhar para os fenômenos históricos presentes na cultura de um país. Desse modo, para evitar a ascensão da barbárie, indivíduo e meio social precisam estar integrados sob uma perspectiva pedagógica crítica e que preserve a singularidade (ADORNO, 2006). A condição coisificada, permeada de formalismos e de grandes narrativas que configuram o modelo de educação universal, reduz o processo de formação do sujeito a pautas objetivas e econômicas, refletidas na cultura, já capturada pelos interesses produtivistas e técnicos.

O papel da História e de seu ensino cotidiano é posto em análise, na hipótese de que suas práticas parecem possibilitar o revigoramento de certos ideais vivenciados na Contemporaneidade. Bloch (2002) pergunta então, “para que serve a História?” e apresenta a inevitabilidade de estabelecer uma relação dinâmica entre passado-presente, um olhar movente perante o objeto e suas causas, negando uma suposta linearidade. Ainda sobre a História, reivindica-se a necessidade de uma história do acontecimento, disposta no acaso, assumindo sua posição perspectiva e o encontro com forças que estão em constante luta. Questiona-se então, esse lugar veloz e rasteiro, antropocêntrico, informativo que assume a História na educação, que desvincula o indivíduo de seu meio social (ADORNO, 2006).

Por fim, exemplificamos alguns dos discursos que ressoam em diversos espaços do Brasil contemporâneo, que ilustram o modelo de homem e de moralidade dissolvidas em muitos cantos da cultura. Entre eles estão a volta da monarquia no Brasil, revisionismos sobre a Ditadura Militar e pedidos de intervenção, ou a suposta Ideologia de Gênero. Ainda nesse sentido, vemos um reposicionamento que tornam frágeis as verdades, principalmente as científicas, pois esse espaço é criador de novas hegemonias e falha na transmissão de seu funcionamento, seus erros e seus equívocos, o que a torna um novo campo "místico" inacessível, e termina por possibilitar o florescer de discursos anticientíficos como os do Movimento Antivacina e Terraplanista, ou a radicalização dos discursos morais.

A proposta de uma educação para a diferença nos faz atentar para o modelo atual de produção maquinária, sempre dissimulado por novos enquadramentos e capturas subjetivas, sob as demarcações dos papéis sociais produzidos, envoltos em valores morais e regimes enunciativos (CORDEIRO; FELDENS, 2016). Resta-nos tomar a Educação em seus encontros com o acaso, buscando fortalecer as micronarrativas da diferença (VIEIRA; FERRONATO, 2017), compreendendo o estado de crise da verdade vividos na Contemporaneidade, 
necessitando desconstruir os ideais modernos que sustentam a ideia do sujeito do conhecimento como figura primordial, possibilitando o olhar às brechas e às rachaduras e a construção de saberes mais horizontais.

AGRADECIMENTOS: Tradução e publicação de artigo financiado pelo Programa de Apoio ao Pesquisador e à Pós-graduação (PROAP) - Edital nº6/2020/PPGED/PROAP/UFS.

\section{REFERÊNCIAS}

ADORNO, T. W. Educação e emancipação. Trad. Wolfegang Leo Maar. 4. ed. Rio de Janeiro: Editora Paz e Terra, 2006.

AGAMBEN, G. O que é o contemporâneo? e outros ensaios. Trad. Vinícius Nicastro. Chapecó/SC: Editora Argos, 2009.

ARENAS, S.; TRUJILLO, A. Significados discursivos sobre ciência e educação na ação política: os relatórios de desenvolvimento. Revista Ibero-Americana de Estudos em Educação, Araraquara, v. 15, n. 1, p. 319-331, jan./mar. 2020. Disponível em: https://periodicos.fclar.unesp.br/iberoamericana/article/viewFile/13076/9114. Acesso em: 4 ago. 2020.

BAPTISTA, M.; PALHANO, T.; DINIZ, E.; SILVA, G. da. Inovações tecnológicas, educação e necessidades do capital. Revista Ibero-Americana de Estudos em Educação, Araraquara, v. 15, n. 1, p. 289-304, jan./mar. 2020. Disponível em:

https://periodicos.fclar.unesp.br/iberoamericana/article/view/12710. Acesso em: 4 ago. 2020.

BLOCH, M. Apologia da história ou o ofício do historiador. Trad. André Telles. Rio de Janeiro: Editora Zahar. 2002.

CORDEIRO, A; FELDENS, D. Vozes do Triunfo: narrativas de si de professoras da educação básica. Revista Tempos e Espaços em Educação, São Cristóvão (Sergipe), v. 11, n. 1, Edição Especial, p. 379-392, dez. 2018. Disponível em:

https://seer.ufs.br/index.php/revtee/article/view/9666. Acesso em: 15 jul. 2020.

DELEUZE, G. Diferença e repetição. Trad. Luiz B. L. Orlandi e Roberto Machado. 2. ed. São Paulo: Graal, 2006. 437 p.

DUQUE, E.; VAZQUEZ, JF. O novo paradigma da educação na promoção de uma sociedade mais inclusiva. Revista Ibero-Americana de Estudos em Educação, Araraquara, v. 15, n. 1, p. 27-49, jan./mar. 2020. Disponível em:

https://periodicos.fclar.unesp.br/iberoamericana/article/view/12632. Acesso em: 4 ago. 2020.

FISHER, R. Foucault e a análise do discurso em educação. Cad. Pesqui., São Paulo, n. 114, p. 197-223, 2001. DOI: http://dx.doi.org/10.1590/S0100-15742001000300009

FOUCAULT, M. Microfísica do poder. Rio de Janeiro: Editora Graal, 1979.

RIAEE - Revista Ibero-Americana de Estudos em Educação, Araraquara, v. 15, n. esp. 3, p. 2314-2331, nov., 2020. E-ISSN: 1982-5587 
FOUCAULT, M. Ordem do discurso. Trad. Laura Sampaio. 3. ed. São Paulo: Edições Loyola, 1996.

FOUCAULT, M. Arqueologia das ciências e sobre a História dos sistemas de

pensamento. Coleção Ditos e escritos. São Paulo: Editora Forense Universitária, 2005. 432 p.

LANUTI, J.; BAPTISTA, M.; RAMOS, E. A diferença de Deleuze na pesquisa em educação: experiências dos pesquisadores do LEPED. Revista Ibero-Americana de Estudos em Educação, Araraquara, v. 15, n. 3, p. 1167-1180, jul./set. 2020. Disponível em: https://periodicos.fclar.unesp.br/iberoamericana/article/view/12627. Acesso em: 4 ago. 2020.

NIETZSCHE, F. Vontade de potência. Trad. Mário D. Ferreira Santos. Rio de Janeiro: Edições de Ouro, 1966.

NIETZSCHE, F. A genealogia da moral. Trad. Paulo Cesar de Souza. São Paulo: Editora Companhia de Bolso, 2009. 176 p.

REIS, D. A. Ditadura militar, esquerdas e sociedade. Rio de Janeiro: Jorge Zahar, 2000.

REIS, D. A. Ditadura e democracia no Brasil: do golpe de 1964 à constituição de 1988. Rio de Janeiro: Zahar, 2014.

VIANA, H. História do Brasil: volume II. 4. ed. São Paulo: Edições Melhoramentos, 1996.

VIEIRA, J.; FERRONATO, C. Linguagem e a crise dos saberes: micronarrativas na pósmodernidade. Revista Tempos e Espaços em Educação, São Cristóvão (Sergipe), v. 10, n. 23, p. 175-186, set./dez. 2017. Disponível em:

https://seer.ufs.br/index.php/revtee/article/view/6519. Acesso em: 18 jan. 2018.

\section{Como referenciar este artigo}

VIEIRA, J. S. M.; CARVALHO, L. O;; FELDENS, D. G. Sintomas do Brasil contemporâneo: tensões discursivas e a educação para a diferença. Revista Ibero-Americana de Estudos em Educação, Araraquara, v. 15, n. esp. 3, p. 2314-2331, nov., 2020. E-ISSN: 1982-5587. DOI: https://doi.org/10.21723/riaee.v15iesp3.14440

Submetido em: 20/07/2020

Revisões requeridas em: 30/08/2020

Aprovado em: 29/09/2020

Publicado em: 30/10/2020 